\title{
PROPHYLACTIC ARGON LASER RETINOPEXY PRIOR TO REMOVAL OF SILICONE OIL: A PILOT STUDY
}

\author{
ADNAN TUFAIL, STEVEN D. SCHWARTZ and ZDENEK J. GREGOR \\ London
}

\begin{abstract}
SUMMARY
Background: Removal of silicone oil following successful retinal detachment surgery is usually performed in an attempt to prevent the complications of silicone oil; however, removal of the oil may result in retinal redetachment.

Purpose: The purpose of this study was to determine whether argon laser retinopexy, 3-6 weeks prior to the removal of silicone oil, reduces the rate of retinal detachment following silicone oil removal.

Methods: A total of 31 eyes of 31 consecutive patients were followed up for a 12 month period after the removal of silicone oil. All patients had undergone retinal reattachment surgery resulting in a clinically attached retina with the absence of residual retinal traction prior to silicone oil removal. A study group of 15 of the 31 eyes received two rows of $360^{\circ}$ of peripheral argon laser retinopexy 3-6 weeks before removal of the silicone oil. The 16 eyes of the previous 16 consecutive patients, who underwent removal of silicone oil without argon laser retinopexy, were used as a control group.

Results: In the study group 1 of 15 eyes $(6.7 \%)$ redetached following the removal of silicone oil and 4 of $16(25 \%)$ redetached in the control group during the 12 month follow-up period from operation.

Conclusions: Prophylactic argon laser retinopexy applied 3-6 weeks before the removal of silicone oil appears to reduce the retinal redetachment rate. $A$ larger prospective randomised trial is needed to confirm these findings.
\end{abstract}

Silicone oil is increasing in use and acceptance in retinal detachment surgery. This increased use brings with it an increase in complications associated with silicone oil itself.

Silicone oil tamponade may result in complications

From: Moorfields Eye Hospital, City Road, London, UK.

Correspondence to: Mr Z. J. Gregor, Moorfields Eye Hospital, City Road, London EC1V 2PD, UK. such as keratopathy, cataract and glaucoma. ${ }^{1-6}$ Glaucoma and keratopathy may be prevented by early removal of silicone oil. ${ }^{7-10}$ However, the removal of silicone oil carries with it a definite ocular morbidity. ${ }^{11}$ The major complications are retinal redetachment, hypotony and expulsive haemorrhage. Redetachment rates between $14 \%$ and $33 \% 6,8,10-12$ have been reported after the removal of silicone oil. The Silicone Study Group Report 6 found that removal of silicone oil increases the chance of recurrent retinal detachment (odds ratio of 2.1, $p=0.09) .{ }^{10}$ This variation may reflect different patient selection and surgical techniques. Casswell and Gregor $^{11}$ have found a redetachment rate of $25 \%$ at our institution. Panretinal photocoagulation prior to silicone oil removal has been used to try to prevent redetachment. ${ }^{8,13}$

Retinal redetachment after removal of silicone oil may result from continuing traction on pre-existing retinal breaks, formation of new breaks, or the exposure breaks that were adequately tamponaded by the surface tension of the silicone oil but that accumulate fluid when the silicone oil is removed. It has been suggested that a lower redetachment rate may occur in patients who have undergone vitrectomy and silicone oil tamponade for complications of diabetic retinopathy. This may be due to the 'walling off' effect of panretinal photocoagulation. ${ }^{14} \mathrm{~A}$ percentage of the late retinal detachments following removal of silicone oil are presumably due to insufficient retinopexy. The reinforcement of the original retinopexy and the creation of a new retinopexy may prevent the reaccumulation of subretinal fluid and so reduce the late retinal detachment rate. This pilot study was undertaken to see whether the placement of two rows of peripheral $360^{\circ}$ argon laser retinopexy could reduce this high redetachment rate associated with silicone oil removal. 


\section{PATIENTS AND METHODS}

A total of 31 eyes of 31 consecutive patients (excluding diabetic patients) that underwent removal of silicone oil were followed up for a period of 12 months. The 31 eyes were in two groups: a study group of 15 eyes that received argon laser retinopexy prior to silicone oil removal, which were entered prospectively during a 10 month period, and a control group of 16 eyes that received no prophylactic argon laser retinopexy during the 10 months immediately preceding the start of the study.

All patients had complicated retinal detachments and proliferative vitreoretinopathy (PVR) necessitating pars plana vitrectomy and silicone oil injection (1000 cS). Before removal of silicone oil all patients were deemed to have no retinal detachment and no evident persistent retinal traction. The indications for the removal of silicone oil were to treat or avoid silicone-oil-induced secondary glaucoma or anterior segment complications or to restore optical media more conducive to useful central vision. Indirect ophthalmoscopy was performed at the end of each operation to confirm that the retina remained attached and to exclude the presence of persisting traction.

The silicone oil was removed by a standard technique as described by Leaver and Lean. ${ }^{9}$ Briefly this consists of floating the silicone oil out of the vitreous cavity through a pars plana incision in a pseudophakic or phakic eye or via the limbus if the eye is aphakic, with physiological infusion fluid allowed to run in simultaneously. In all cases the retina was thought to be stable and attached prior to removal of the silicone oil and the anterior segment complications did not override the status of retinal reattachment in any circumstances.

The study group of 15 eyes of 15 patients were entered prospectively during a continuous 10 month period. Informed consent was obtained in each case. These patients received prophylactic argon laser photocoagulation 3-6 weeks prior to having silicone oil removed. Photocoagulation was applied either using the indirect ophthalmoscope or via slit lamp delivery. The laser spots were placed in two rows encompassing $360^{\circ}$ of the anterior retina on and immediately posterior to the scleral buckle and/or the original retinopexy marks. The study group was followed up for 12 months from the date of removal of silicone oil. Any complications were noted.

The surgery in the control group was performed by the same surgical team and only differed from that in the study group in not having argon laser applied prior to the removal of silicone oil.

\section{RESULTS}

Silicone oil was removed from 31 eyes of 31 patients during the follow-up period. In the study group of 15 eyes, 6 had giant retinal tears and 9 had rhegmatogenous retinal detachments. All cases were complicated by PVR (Table I). The study group had a mean age of 40 years (range 12-65 years). The control group of 16 eyes included 4 giant retinal tears and 8 rhegmatogenous detachments. Again all cases were complicated by PVR. The mean age in the control group was 42 years (range 29-61 years).

In the study group the number of prophylactic argon burns varied from 562 to 973 . One of 15 (6.7\% of the total) eyes redetached after the removal of the oil in this group during the follow-up period. This patient was referred to our institution for the treatment of a tractional retinal detachment following a central retinal vein occlusion. $\mathrm{He}$ underwent successful vitrectomy and delamination of fibrovascular membranes. One month post-operatively he suffered a secondary rhegmatogenous retinal detachment and PVR. This required the further operation including retinotomy/retinectomy and silicone oil injection. After 6 months peripheral retinal photocoagulation was performed 3 weeks prior to the removal of silicone oil. The retina redetached 3 months post-operatively.

Four redetachments and one case of choroidal detachment and hypotony occurred in the control group not receiving laser treatment before the removal of silicone oil. One of the patients in this group is a 41-year-old man who had a lensectomy as a child for congenital cataracts. He developed a rhegmatogenous retinal detachment which was treated with drainage, cryotherapy, buckle and the injection of $\mathrm{C}_{3} \mathrm{~F}_{8}$ gas/air mixture. Nine months later he developed an inferior retinal detachment with PVR which required a vitrectomy, the use of perfluorocarbon liquids, endolaser and silicone oil injection to reattach the retina. One month after removal of the silicone oil there was a subtotal redetachment with the development of PVR. Two cases involved rhegmatogenous detachments that were referred after having previously undergone one or more attempts at reattachment without using silicone oil. These cases were complicated by PVR. The fourth redetachment in the control group was in an eye with a giant retinal tear in a high myope that redetached.

In the 16 patients not receiving peripheral retinal photocoagulation before the removal of silicone oil,

Table I. Patient characteristics

\begin{tabular}{lcc}
\hline & $\begin{array}{c}\text { Study group } \\
\text { (prophylactic laser) }\end{array}$ & $\begin{array}{c}\text { Control group } \\
\text { (no prophylactic laser) }\end{array}$ \\
\hline $\begin{array}{l}\text { No. of cases } \\
\text { Sex ratio (M: F) }\end{array}$ & 15 & 16 \\
Median age (years) & 40 (range 12-65) & 42 (range 29-61) \\
$\begin{array}{l}\text { Follow-up (months) } \\
\text { Giant retinal tears }\end{array}$ & 12 & 12 \\
Proliferative vitreo- & 6 & 4 \\
$\quad$ retinopathy present & 15 & 16 \\
Redetachments & $1(6.7 \%)$ & $4(25 \%)$ \\
\hline
\end{tabular}


there were 4 retinal redetachments after removal of silicone oil, giving a redetachment rate of $25 \%$.

\section{DISCUSSION}

Silicone oil is an accepted form of intraocular tamponade for complicated retinal detachments. In patients with PVR it has been shown to be superior to $\mathrm{C}_{3} \mathrm{~F}_{8}$ gas with respect to visual acuity and macular attachment. ${ }^{15}$ Silicone oil can cause anterior segment complications. ${ }^{1-6}$ There is evidence that these complications can be prevented by its early removal. ${ }^{7-9}$ In addition, removal of silicone oil is associated with a better visual outcome. ${ }^{10}$ However, there is a significant risk of redetachment following the removal of silicone oil. The reported redetachment rate varies between studies from $14 \%$ to $33 \%$., $, 8,10-12$

The low redetachment rate in this study following the removal of silicone oil of $6.7 \%$ (1 case in 15) in patients receiving peripheral retinal photocoagulation in two rows encompassing $360^{\circ}$ of peripheral retina is lower than expected compared both with our previously reported redetachment rate from our institution $(25 \%)^{11}$ and with the rate in the patients not receiving photocoagulation in this study $(25 \%)$.

Possible explanations for the difference between the study group and the control group are: (1) the two groups are not comparable as the patients were not randomised, (2) the effect is due to chance alone as the numbers in the study are small, (3) the effect is real and prophylactic retinal photocoagulation does reduce the rate of redetachment, (4) part of the difference is due to the different indications for surgery in the two groups, which may have different redetachment rates. A previous report by Casswell and Gregor ${ }^{11}$ suggests that the redetachment rate after the removal of silicone oil may be higher in eyes with PVR as opposed to those with giant retinal tears, although the difference was not found to be statistically significant in this study.

The eyes at risk of redetachment are those with persisting traction anterior to the buckle, but it may be difficult to recognise this. Most redetachments are due to reopening of old holes or the creation of new ones and occur within a few weeks of silicone oil removal. Indeed the retinae in all patients in this study were thought to be completely attached prior to the removal of silicone oil and without residual traction. Removal of silicone oil may also result in retinal detachment in cases where the surface tension/tamponade effect of the oil is enough to keep occult breaks closed without complete retinopexy. Removal of silicone oil in a subset of the eyes may unmask retinopexy that is only sufficient to keep a break closed in the presence of the surface tension/ tamponade effect of silicone oil. Thus the creation of a barrier or reinforcement to the previous retinopexy is a logical way to prevent redetachment.
Photocoagulation prior to silicone oil removal is simple, well tolerated and had no complications in our experience. The photocoagulation was performed 3-6 weeks before removal of the silicone oil to allow the laser reaction to establish itself.

The preliminary results show a reduction in redetachment rate from $25 \%$ to $6.7 \%$. This seems very encouraging, but in order to define the role of prophylactic retinal photocoagulation more clearly, further study seems indicated.

S.D.S. was funded in part by the Ahmanson Foundation, Los Angeles.

Key words: Laser surgery, Prevention, Retina, Retinal detachment, Silicone oil, Surgical complications.

\section{REFERENCES}

1. Sternberg PJ, Hatchell DL, Foulks GN, et al. The effect of silicone oil on the cornea. Arch Ophthalmol 1985; 103:90-4.

2. Haut J, Ullern M, Chermet M, et al. Complications of intraocular injections of silicone combined with vitrectomy. Ophthalmologica 1980;180:29-35.

3. Yeo JH, Glaser BM, Michels RG. Silicone oil in the treatment of complicated retinal detachments. Ophthalmology 1987;94:1109-13.

4. Leaver PK, Grey RH, Garner A. Silicone oil injection in the treatment of massive preretinal retraction. II. Late complications in 93 eyes. $\mathrm{Br} \mathrm{J}$ Ophthalmol 1979;63:361-7.

5. Kanski JJ, Daniel R. Intravitreal silicone injection in retinal detachment. Br J Ophthalmol 1973;57:542-5.

6. Franks WA, Leaver PK. Removal of silicone oil: rewards and penalties. Eye 1991;5:333-7.

7. Casswell AG, Gregor ZJ. Silicone oil removal. I. The effect on the complications of silicone oil. $\mathrm{Br} \mathrm{J}$ Ophthalmol 1987;71:893-7.

8. Gonvers M. Temporary use of intraocular silicone oil in the treatment of detachment with massive periretinal proliferation: preliminary report. Ophthalmologica 1982;184:210-8.

9. Leaver PK, Lean JS. Management of giant retinal tears using vitrectomy and silicone oil/fluid exchange: a preliminary report. Trans Ophthalmol Soc UK 1981;101:189-91.

10. Hutton WL, Azen SP, Blumenkranz MS, et al. The effects of silicone oil removal. Silicone Study Report 6 . Arch Ophthalmol 1994;112:778-85.

11. Casswell AG, Gregor ZJ. Silicone oil removal. II. Operative and postoperative complications. $\mathrm{Br} \mathrm{J}$ Ophthalmol 1987;71:898-902.

12. Ruellan YM, Roussat B. Decollement de retine: tamponnement interne provisoire par huile de silicone après vitrectomie: résultats anatomiques et fonctionnels. J Fr Ophtalmol 1985;8:117-24.

13. Gnad H, Skorpik C, Paroussis $P$, et al. Funktionelle und anatomische Resultate nach temporäre Silikonlimplantation. Klin Monatsbl Augenheilkd 1984;185:364-7.

14. Pearson RV, McLeod D, Gregor ZJ. Removal of silicone oil following diabetic vitrectomy. $\mathrm{Br} \mathrm{J}$ Ophthalmol 1993;77:204-7.

15. Vitrectomy with silicone oil or perfluoropropane gas in eyes with severe proliferative vitreoretinopathy: results of a randomised clinical trial. Silicone Study Report 2. Arch Ophthalmol 1992;110:780-92. 